Article

\title{
Synthesis and Performance of 6FDA-Based Polyimide-Ionenes and Composites with Ionic Liquids as Gas Separation Membranes
}

\author{
Kathryn E. O’Harra ${ }^{1}$, Irshad Kammakakam ${ }^{1}{ }^{1}$, Emily M. Devriese ${ }^{1}$, Danielle M. Noll ${ }^{1}$, \\ Jason E. Bara ${ }^{1, *(\mathbb{D})}$ and Enrique M. Jackson ${ }^{2}$ \\ 1 Department of Chemical \& Biological Engineering, University of Alabama, Tuscaloosa, AL 35487-0203, USA \\ 2 NASA Marshall Space Flight Center, Huntsville, AL 35812, USA \\ * Correspondence: jbara@eng.ua.edu; Tel.: +(205) 348-6836
}

Received: 3 June 2019; Accepted: 29 June 2019; Published: 3 July 2019

\begin{abstract}
Three new isomeric 6FDA-based polyimide-ionenes, with imidazolium moieties and varying regiochemistry (para-, meta-, and ortho- connectivity), and composites with three different ionic liquids (ILs) have been developed as gas separation membranes. The structural-property relationships and gas separation behaviors of the newly developed 6FDA polyimide-ionene + IL composites have been extensively studied. All the 6FDA-based polyimide-ionenes exhibited good compatibility with the ILs and produced homogeneous hybrid membranes with the high thermal stability of $\sim 380{ }^{\circ} \mathrm{C}$. Particularly, [6FDA I4A pXy][Tf $\left.{ }_{2} \mathrm{~N}\right]$ ionene + IL hybrids having $\left[\mathrm{C}_{4} \mathrm{mim}\right]\left[\mathrm{Tf}_{2} \mathrm{~N}\right]$ and [Bnmim] $\left[\mathrm{Tf}_{2} \mathrm{~N}\right]$ ILs offered mechanically stable matrixes with high $\mathrm{CO}_{2}$ affinity. The permeability of $\mathrm{CO}_{2}$ was increased by factors of 2 and 3 for $\mathrm{C}_{4}$ mim and Bnmim hybrids (2.15 to 6.32 barrers), respectively, compared to the neat [6FDA I4A pXy] $\left[\mathrm{Tf}_{2} \mathrm{~N}\right]$ without sacrificing their permselectivity for $\mathrm{CO}_{2} / \mathrm{CH}_{4}$ and $\mathrm{CO}_{2} / \mathrm{N}_{2}$ gas pairs.
\end{abstract}

Keywords: 6FDA polyimides; ionenes; Hybrid Membranes; $\mathrm{CO}_{2}$ Separation

\section{Introduction}

Polyimides (PIs) have been extensively considered as materials for gas separation membranes because of their excellent mechanical and thermal stability as well as their intrinsic separation properties, particularly for $\mathrm{CO}_{2} / \mathrm{CH}_{4}$ and $\mathrm{CO}_{2} / \mathrm{N}_{2}$ separations [1-3]. Furthermore, the synthesis and functionalization of PIs are neither problematic nor expensive, and it is easy to fabricate ultra-thin membranes using current commercial fabrication processes. The gas separation performance of the polymeric membranes is directly related to the chemical structure of the polymer and morphology. Therefore, research on the structures and properties of polymers is of great interest and an enduring challenge in the development of gas separation membranes. Research into the structure-property relationships of PIs with the aim of developing enhanced gas separation application membranes has mainly focused on (1) the inclusion of flexible or contorted substituent groups into the PI backbone to enhance processability [4-6], (2) the incorporation of bulky and polar groups in order to improve the permeability/selectivity tradeoffs $[7,8],(3)$ the enhancement of the inter-chain packing density and the dimensions of free volume elements $[9,10]$, and (4) the improvement of the thermal and mechanical resistance of such membranes to harsh environments [11-13].

Among the various research reports on PI membrane materials to explore the relationship between the chemical structures and the gas transport properties, fluorinated dianhydride, 4,4'-(hexafluoroisopropylidene)-diphthalic anhydride (commonly abbreviated as 6FDA) based PIs have recently dominated the literature and are observed to have much higher $\mathrm{CO}_{2}$ permeabilities 
with reasonable selectivities [11,14]. The 6FDA-PI contains $-\mathrm{CF}_{3}$ groups which restrict the torsional motion of the neighboring phenyl rings, and thus, prevents efficient chain packing, which yields high fractional free volume (FFV) in the polymeric matrix and enhances the permeability. On the other hand, there have been several attempts to improve the selectivity of such PIs by introducing $\mathrm{CO}_{2}$-philic species, such as ionic liquids (ILs) [15,16], amines [17], or poly(ethylene oxide)s [18].

ILs have recently emerged as promising $\mathrm{CO}_{2}$ separation materials due to their $\mathrm{CO}_{2}$ affinity and high $\mathrm{CO}_{2}$ gas selectivity over $\mathrm{N}_{2}$ and $\mathrm{CH}_{4}[19,20]$. Polymeric membranes either containing or built from ILs offer virtually endless possibilities for the design of materials for enhanced gas separation applications. Among the cations commonly used to form ILs or Poly(IL)s, including phosphonium [21], ammonium [22] and pyridinium [23], the imidazolium cations have garnered the more interest due to their versatile nature and tunable structures [24,25]. Furthermore, it is highly feasible to graft pendant imidazolium cations to most conventional polymers such as poly(ether sulfone)s [26], poly(ether ketone)s [27], and polyimides [8,28]. Nonetheless, there have been just a handful of reports considering those pendant imidazolium polymers in $\mathrm{CO}_{2}$ separation membranes, especially from a PI backbone. It also should be noted that pendant imidazolium groups can be cleaved from polymer backbones at elevated temperatures (nearly $250{ }^{\circ} \mathrm{C}$ ) [29].

Ionenes are charged polymers in which the ionic moieties are contained directly within the polymer backbone rather than as pendants. Ionenes are also of growing interest as a material platform for gas separation, as well as many other applications, including electrolytes for fuel cells and Li-ion batteries [30-32]. With a polycationic structure (mainly as a quaternary ammonium form), ionenes function as a robust matrix that yields high thermal stability and provides Coulombic interactions between polymer chains, retaining the properties of ILs. Recently, we have focused on the design and synthesis of various bis(imidazole) monomers containing aromatic imide or amide linkages that can yield thermally robust imidazolium ionenes [33,34]. These "high-performance" ionenes can be prepared via simple synthetic strategies without significant additional production costs and are well-suited to separate $\mathrm{CO}_{2}$ from light gases such as $\mathrm{N}_{2}$ and $\mathrm{CH}_{4}$ with high selectivity and durability [34].

Herein, we report the design, synthesis, and gas separation performance of a series of three 6FDA-based PI-ionenes and composites with three imidazolium ILs: $\left[\mathrm{C}_{2} \operatorname{mim}\right]\left[\mathrm{Tf}_{2} \mathrm{~N}\right],\left[\mathrm{C}_{4} \mathrm{mim}\right]\left[\mathrm{Tf}_{2} \mathrm{~N}\right]$, and $[\mathrm{Bnmim}]\left[\mathrm{Tf}_{2} \mathrm{~N}\right]$. As depicted in Scheme 1, three imide-functionalized monomers were prepared via the reaction of 6FDA with imidazole-aniline molecules connected at para-, meta-, or ortho positions. A step-growth polycondensation of these three 6FDA-imidazole monomers with a stoichiometric equivalent of an $\alpha, \alpha^{\prime}$-dichloroxylene (para-, meta-, and ortho) via Menshutkin reactions yielded corresponding 6FDA-based PI-ionenes (Scheme 2). The structural-property relationships and gas separation behaviors of newly developed PI-ionenes and composites containing ILs are analyzed. 


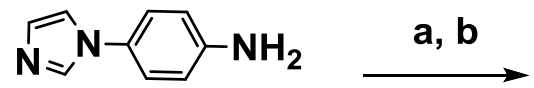

I4A<smiles>O=C1OC(=O)c2cc(C(c3ccc4c(c3)C(=O)OC4=O)(C(F)(F)F)C(F)(F)F)ccc21</smiles>

6FDA<smiles>Nc1cccc(-n2ccnc2)c1</smiles><smiles>Nc1ccccc1-n1ccnc1</smiles>

I2A<smiles>CC(C)Oc1ccc(C(c2ccc3c(c2)C(=O)N(c2ccc(-n4ccnc4)cc2)C3=O)(C(F)(F)F)C(F)(F)F)cc1</smiles><smiles>O=C1c2ccc(C(F)(c3ccc4c(c3)C(=O)N(c3cccc(-n5ccnc5)c3)C4=O)C(F)(F)F)cc2C(=O)N1c1cccc(-n2ccnc2)c1</smiles>

6FDA I3A

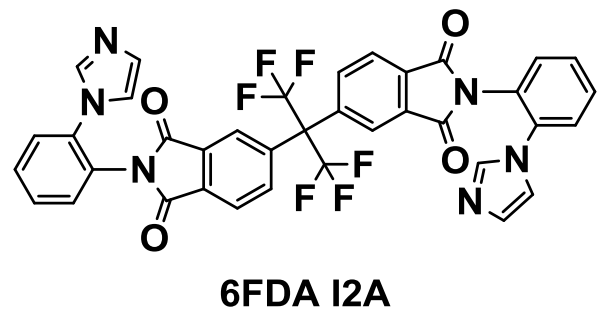

Scheme 1. Synthesis of aromatic, fluorinated dianhydride, $4,4^{\prime}$-(hexafluoroisopropylidene)-diphthalic anhydride (6FDA)-based imide monomers. a: DMF $\left(5^{\circ} \mathrm{C}, 1 \mathrm{~h}\right.$; RT, $\left.24 \mathrm{~h}\right)$; b: Toluene $\left(125^{\circ} \mathrm{C}, 24 \mathrm{~h}\right)$; c: $\mathrm{Ac}_{2} \mathrm{O}\left(70{ }^{\circ} \mathrm{C}, 16 \mathrm{~h}\right)$. 
<smiles>O=C1c2ccc(C(c3ccc4c(c3)C(=O)N(c3ccc(-n5ccnc5)cc3)C4=O)(C(F)(F)F)C(F)(F)F)cc2C(=O)N1c1ccc(-n2ccnc2)cc1</smiles>

6FDA I4A<smiles>O=C1c2ccc(-n3ccnc3)cc2C(=O)N1c1cccc(N2C(=O)c3ccc(C(c4cccc(-n5ccnc5)c4)(C(F)(F)F)C(F)(F)F)cc3C2=O)c1</smiles>

6FDA I3A<smiles>O=C1c2ccc(C(c3ccc4c(c3)C(=O)N(c3ccccc3-n3ccnn3)C4=O)(C(F)(F)F)C(F)(F)F)cc2C(=O)N1c1ccccc1-n1ccnc1</smiles>

6FDA I2A<smiles>ClCc1ccc(CCl)cc1</smiles>

pDCXy

mDCXy<smiles>ClCc1ccccc1CCl</smiles>

$\Theta$

$\mathrm{Tf}_{2} \mathrm{~N}$

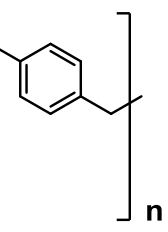

[6FDA I4A pXy][Tf $\left.{ }_{2} N\right]$

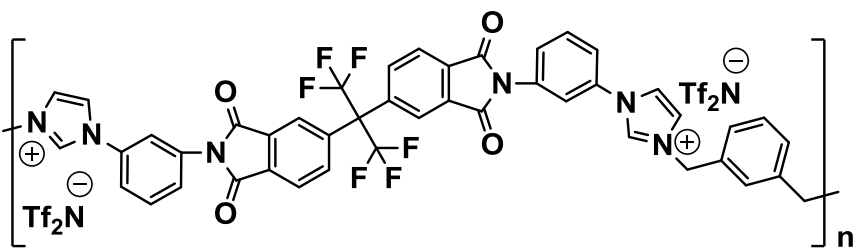

[6FDA I3A mXy][Tf $\left.{ }_{2} N\right]$

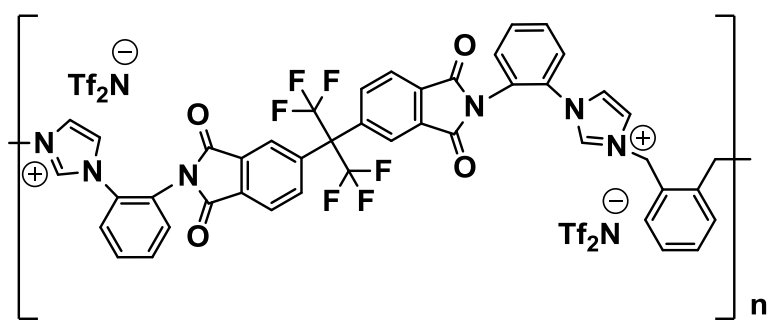

[6FDA I2A oXy][Tf $\left.{ }_{2} N\right]$

Scheme 2. Synthesis of imidazolium polyimide-ionene derivatives. a: DMF $\left(120^{\circ} \mathrm{C}, 24 \mathrm{~h}\right) ; \mathrm{b}: \mathrm{H}_{2} \mathrm{O}$, $\mathrm{LiTf}_{2} \mathrm{~N}(\mathrm{RT}, 24 \mathrm{~h})$.

\section{Materials and Methods}

\subsection{Materials}

2-fluoronitrobenzene ("2-FNB") (99\%), 3-fluoronitrobenzene (“3-FNB") (99\%), and 4-fluoronitrobenzene ("4-FNB") (98\%) were purchased from Oakwood Chemical (Estill, SC, USA). Imidazole (99\%) was purchased from Aldrich (St. Louis, MO, USA). Potassium carbonate (99\%, 
anhydrous) and $\mathrm{Pd} / \mathrm{C}(10 \%$ on $\mathrm{C}$, Type 487$)$ were purchased from BeanTown Chemical (Hudson, $\mathrm{NH}, \mathrm{USA}$ ). $\alpha, \alpha^{\prime}$-Dichloro-p-xylene. (pDCXy, >98\%), $\alpha, \alpha^{\prime}$-Dichloro-m-xylene. (mDCXy, $\left.>96 \%\right)$, and $\alpha, \alpha^{\prime}$-Dichloro-o-xylene (oDCXy, $>97 \%$ ) were purchased from TCI (Tokyo Chemical Industry) (Portland, OR, USA). Lithium bis-trifluoromethanesulfonimide (HQ-115) was purchased from 3M (Minneapolis, MN, USA). Ethanol (EtOH, 200 proof), N-methylpyrrolidone (NMP, ACS grade), dimethyl sulfoxide (DMSO, ACS grade), diethyl ether $\left(\mathrm{Et}_{2} \mathrm{O}\right)$ and toluene (anhydrous) were purchased from VWR (Atlanta, GA, USA). Acetic anhydride $\left(\mathrm{Ac}_{2} \mathrm{O},>99 \%\right)$ was purchased from Alfa Aesar (Tewksbury, MA, USA). $\mathrm{SiO}_{2}$ (Celite 545) was purchased from Acros Organics. (Geel, Belgium) 4,4'-(hexafluoroisopropylidene)diphthalic anhydride (6FDA) was purchased from Akron Polymer Systems (Akron, OH, USA). All materials were used as obtained, without further purification.

\subsection{Characterization}

${ }^{1} \mathrm{H}-\mathrm{NMR}$ and ${ }^{13} \mathrm{C}-\mathrm{NMR}$ data were obtained using $360 \mathrm{MHz}$ or $500 \mathrm{MHz}$ Bruker Avance instruments. FT-IR data were collected on a Perkin Elmer Spectrum Two ATR FT-IR (Shelton, CT, USA). The thermal stabilities of these PI-ionenes with ILs were evaluated by thermogravimetric analysis (TGA) at a heating rate of $10{ }^{\circ} \mathrm{C} \mathrm{min}^{-1}$ under an $\mathrm{N}_{2}$ atmosphere (Seiko TG/DTA 7300). The glass transition temperature $\left(\mathrm{T}_{\mathrm{g}}\right.$ ) of each PI-ionene was observed by DSC (TA Instruments, DSC Q20) from 20 to $300{ }^{\circ} \mathrm{C}$ with a scan rate of $10^{\circ} \mathrm{C} \mathrm{min}^{-1}$ under $\mathrm{N}_{2}$. The wide-angle X-ray diffraction (WAXD) patterns of the materials were measured using a Bruker D8 Discover diffractometer by employing a scanning rate of $4^{\circ} \mathrm{min}^{-1}$ in a $2 \theta$ range from $5^{\circ}$ to $70^{\circ}$ with a $\operatorname{Co} K \alpha 1 X$-ray $(\lambda=0.17886 \mathrm{~nm})$ source. The $\mathrm{d}$-spacing values were calculated using Bragg's law $(\mathrm{d}=\lambda / 2 \sin \theta)$ and the Diffrac-EVA software. The number average molecular weight $\left(\mathrm{M}_{\mathrm{N}}\right)$ values of the PI-ionenes were determined via MALDI-TOF MS (Bruker Ultraflex).

\subsection{Synthesis of Imidazole-Aniline Precursors}

\subsubsection{Synthesis of 4-(1H-imidazol-1-yl)aniline "I4A"}

The synthesis of 4-(1H-imidazol-1-yl)aniline (I4A) starting from imidazole and 4-FNB was reported in our previous work [35]. ${ }^{1} \mathrm{H}$ NMR $\left(500 \mathrm{MHz}\right.$, DMSO- $\left.d_{6}\right) \delta 7.95(\mathrm{~s}, 1 \mathrm{H}), 7.48(\mathrm{~s}, 1 \mathrm{H}), 7.22(\mathrm{~d}, 2 \mathrm{H}), 7.01$ $(\mathrm{s}, 1 \mathrm{H}), 6.64(\mathrm{~d}, J=8.8,2 \mathrm{H}), 5.26(\mathrm{~s}, 2 \mathrm{H})$.

\subsubsection{Synthesis of 3-(1H-imidazol-1-yl)aniline "I3A"}

The meta-derivative (I3A) was synthesized by a similar method. Imidazole ( $48.25 \mathrm{~g}, 709 \mathrm{mmol})$, 3-FNB (50 g, $354 \mathrm{mmol})$, and $\mathrm{K}_{2} \mathrm{CO}_{3}(53.76 \mathrm{~g}, 389 \mathrm{mmol})$ were added with $350 \mathrm{~mL}$ of DMSO to a $1000 \mathrm{~mL}$ round-bottom-flask. The vessel was capped with a rubber stopper and vented with a needle through the cap, to prevent the buildup of pressure in the flask upon heating. The reaction was heated to $110^{\circ} \mathrm{C}$ overnight. The reaction was cooled to room temperature and poured into $600 \mathrm{~mL}$ of $\mathrm{DI} \mathrm{H}_{2} \mathrm{O}$ to precipitate the product and remove excess imidazole. The product was filtered and then stirred in $250 \mathrm{~mL}$ of $\mathrm{Et}_{2} \mathrm{O}$ for $24 \mathrm{~h}$ to remove unreacted 3-FNB. The purified and dried product was collected as bright yellow powder. The imidazole-nitrophenyl product was reduced in $\mathrm{EtOH}(350 \mathrm{~mL})$ with $\mathrm{Pd} / \mathrm{C}$ $(1.70 \mathrm{~g})$, with a $\mathrm{H}_{2}$ feed $(30 \mathrm{psi})$. The product was recovered and purified as a tan solid $(49.9 \mathrm{~g}, 89 \%)$. ${ }^{1} \mathrm{H}$ NMR $\left(360 \mathrm{MHz}\right.$, DMSO- $\left.d_{6}\right) \delta 8.08(\mathrm{~s}, 1 \mathrm{H}), 7.57(\mathrm{t}, J=1.3 \mathrm{~Hz}, 1 \mathrm{H}), 7.13(\mathrm{t}, J=1.3 \mathrm{~Hz}, 1 \mathrm{H}), 7.08(\mathrm{~s}, 2 \mathrm{H})$, $6.73(\mathrm{t}, 1 \mathrm{H}), 6.72-6.67(\mathrm{~m}, 1 \mathrm{H}), 6.60-6.53(\mathrm{~m}, 1 \mathrm{H}), 5.41(\mathrm{~s}, 2 \mathrm{H})$.

\subsubsection{Synthesis of 2-(1H-imidazol-1-yl)aniline ("I2A")}

The synthesis of 2-(1H-imidazol-1-yl)aniline (I2A) starting from imidazole and 2-FNB was reported in our previous work [35]. ${ }^{1} \mathrm{H}$ NMR $\left(360 \mathrm{MHz}\right.$, DMSO- $\left.d_{6}\right) \delta 7.74(\mathrm{t}, J=1.1 \mathrm{~Hz}, 1 \mathrm{H}), 7.30(\mathrm{t}, J=1.3 \mathrm{~Hz}$, $1 \mathrm{H}), 7.14(\mathrm{ddd}, \mathrm{J}=8.1,7.3,1.6 \mathrm{~Hz}, 1 \mathrm{H}), 7.10(\mathrm{t}, \mathrm{J}=1.1 \mathrm{~Hz}, 1 \mathrm{H}), 7.03(\mathrm{dd}, \mathrm{J}=7.8,1.6 \mathrm{~Hz}, 1 \mathrm{H}), 6.86(\mathrm{dd}$, $J=8.1,1.4 \mathrm{~Hz}, 1 \mathrm{H}), 6.64(\mathrm{td}, J=7.5,1.4 \mathrm{~Hz}, 1 \mathrm{H}), 5.06(\mathrm{~s}, 2 \mathrm{H})$. 


\subsection{Synthesis of Aromatic Polyimide Monomers}

2.4.1. Synthesis of 5,5' -(perfluoropropane-2,2-diyl)bis(2-(4-(1H-imidazol-1yl)phenyl)isoindoline-1, 3-dione) ("6FDA-I4A")

The synthesis of 5,5'-(perfluoropropane-2,2-diyl)bis(2-(4-(1H-imidazol-1yl)phenyl)isoindoline-1, 3-dione) ("6FDA I4A") from 6FDA and I4A was previously introduced in our previous work [33]. ${ }^{1} \mathrm{H}$ NMR $\left(360 \mathrm{MHz}, \mathrm{DMSO}-\mathrm{d}_{6}\right) \delta 8.34(\mathrm{~d}, 2 \mathrm{H}), 8.25(\mathrm{~d}, 2 \mathrm{H}), 8.02(\mathrm{~d}, 2 \mathrm{H}), 7.88-7.75(\mathrm{~m}, 8 \mathrm{H}), 7.62(\mathrm{dt}, 2 \mathrm{H})$, 7.17 (s, 4H). ${ }^{13} \mathrm{C}$ NMR $\left(126 \mathrm{MHz}, \mathrm{DMSO}-d_{6}\right) \delta 166.50,166.35,149.34,136.94,136.18,135.73,134.47$, $133.63,132.37,130.66,130.16,129.28,128.50,118.74,118.36,113.03,65.95$.

2.4.2. Synthesis of 5,5'-(perfluoropropane-2,2-diyl)bis(2-(3-(1H-imidazol-1-1)phenyl)isoindoline-1, 3-dione) ("6FDA-I3A")

5,5'-(perfluoropropane-2,2-diyl)bis(2-(3-(1H-imidazol-1-1)phenyl)isoindoline-1,3-dione) ("6FDA I3A") was synthesized according to a similar procedure. 6FDA (13.95 g, $31.4 \mathrm{mmol})$ was added to a $250 \mathrm{~mL}$ round-bottom flask with $50 \mathrm{~mL}$ of DMF. The reaction was cooled to $5^{\circ} \mathrm{C}$ and stirred for $1 \mathrm{~h}$. I3A $(10.00 \mathrm{~g}, 62.8 \mathrm{mmol})$ was then added to the flask, and the vessel was allowed to warm to room temperature overnight while stirring. Toluene $(15 \mathrm{~mL})$ was then added to the flask and the reaction was equipped with a reflux condenser. The vessel was then heated at $125^{\circ} \mathrm{C}$ for $24 \mathrm{~h}$. The solution was then cooled, and toluene and some DMF were removed via rotary evaporation. The remaining solution was poured into $600 \mathrm{~mL}$ of DI $\mathrm{H}_{2} \mathrm{O}$ to precipitate the product. The solids were filtered and washed with $2 \times 100 \mathrm{~mL}$ of $\mathrm{DI} \mathrm{H}_{2} \mathrm{O}$, collected and dried for $24 \mathrm{~h}$ at $120^{\circ} \mathrm{C}$ under vacuum, yielding the product as an off-white powder $(13.9 \mathrm{~g}, 61 \%) .{ }^{1} \mathrm{H}$ NMR $\left(500 \mathrm{MHz}, \mathrm{DMSO}-d_{6}\right) \delta 8.29-8.22(\mathrm{~m}, 4 \mathrm{H})$, $8.03(\mathrm{~d}, J=8.0 \mathrm{~Hz}, 2 \mathrm{H}), 7.84-7.77(\mathrm{~m}, 6 \mathrm{H}), 7.75-7.62(\mathrm{~m}, 4 \mathrm{H}), 7.50-7.45(\mathrm{~m}, 2 \mathrm{H}), 7.16(\mathrm{~s}, 2 \mathrm{H}) .{ }^{13} \mathrm{C} \mathrm{NMR}$ $\left(500 \mathrm{MHz}, \mathrm{DMSO}-d_{6}\right) \delta$ [ppm] 166.20, 152.99, 135.94, 133.38, 130.97, 130.24, 126.47, 125.08, 124.25, 120.87, 119.96, 119.96, 118.53, 116.08, 107.73, 97.76, 70.20. $[\mathrm{M}]\left[\mathrm{H}^{+}\right]$: calculated = 726.1450; found = 726.1439.

2.4.3. Synthesis of 5,5'-(perfluoropropane-2,2-diyl)bis(2-(2-(1H-imidazol-1yl)phenyl)isoindoline-1, 3-dione) ("6FDA I2A")

5,5'-(perfluoropropane-2,2-diyl)bis(2-(2-(1H-imidazol-1yl)phenyl)isoindoline-1,3-dione) (“6FDA I2A") was synthesized according to a similar procedure. 6FDA $(4.00 \mathrm{~g}, 9.00 \mathrm{mmol})$ was added to a round-bottom flask with $30 \mathrm{~mL}$ of DMF. The reaction was cooled to $5^{\circ} \mathrm{C}$ and stirred for $1 \mathrm{~h}$. I2A $(3.01 \mathrm{~g}$, $18.9 \mathrm{mmol}$ ) was then added to the flask, and the vessel was allowed to warm to room temperature and stirred overnight. Toluene $(10 \mathrm{~mL})$ was then added to the flask, and the reaction was equipped with a reflux condenser. The vessel was then heated at $125^{\circ} \mathrm{C}$ for $24 \mathrm{~h}$. The solution was cooled, and toluene and some DMF were removed via rotary evaporation. The remaining solution was poured into $400 \mathrm{~mL}$

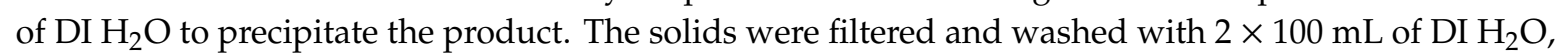
collected, and dried for $24 \mathrm{~h}$ at $120^{\circ} \mathrm{C}$ under vacuum. The solids were added to a round-bottom flask with a reflux condenser and $25 \mathrm{~mL}$ of $\mathrm{Ac}_{2} \mathrm{O}$. To complete ring closure from the amic acid to the imide function, the solution was heated to $75{ }^{\circ} \mathrm{C}$ for $24 \mathrm{~h}$. The product was precipitated in and washed with $\mathrm{DI} \mathrm{H}_{2} \mathrm{O}$, followed by drying at $120^{\circ} \mathrm{C}$ overnight yielding the product as a crystalline brown powder (5.80 g, 88\%). ${ }^{1} \mathrm{H}$ NMR (500 MHz, DMSO-d 6 ) $\delta 8.93-8.84(\mathrm{~m}, 2 \mathrm{H}), 8.46(\mathrm{~m}, 2 \mathrm{H}), 8.17-7.95(\mathrm{~m}, 6 \mathrm{H})$, 7.85-7.75 (m, 5H), 7.75-7.69 (m, 4H). ${ }^{13} \mathrm{C}$ NMR (500 MHz, DMSO- $\left.d_{6}\right) \delta[\mathrm{ppm}] 165.36,158.72,154.60$, $134.53,131.24,130.34,129.77,129.68,129.49,129.30,127.31,125.34,124.20,122.94,120.08,118.36,116.41$, 115.23, 71.55. $[\mathrm{M}]\left[\mathrm{H}^{+}\right]$: calculated $=726.1450$; found $=726.1443$.

\subsection{Formation of Polyimide-Ionenes}

\subsubsection{Synthesis of [6FDA I4A pXy][Tf $2 \mathrm{~N}]$}

6FDA-I4A ionenes were synthesized according to Scheme 2 using the following procedure: 6FDA-I4A (15.00 g, $20.6 \mathrm{mmol})$ and pDCXy (3.614 g, $20.6 \mathrm{mmol})$ were added with $180 \mathrm{~mL}$ of anhydrous 
DMF to a round-bottom heavy-walled pressure vessel and was sealed. The reaction was heated to $120{ }^{\circ} \mathrm{C}$ for $24 \mathrm{~h}$. The product (as $\mathrm{Cl}^{-}$salt) was precipitated in an Erlenmeyer flask containing $500 \mathrm{~mL}$ of DI water with 3 eq. of $\mathrm{LiTf}_{2} \mathrm{~N}(14.82 \mathrm{~g}, 51.6 \mathrm{mmol})$. The [6FDA I4A pXy] ionene solution was stirred for $24 \mathrm{~h}$ to allow for the anion exchange. The product was then filtered and dried in a vacuum oven at $120{ }^{\circ} \mathrm{C}$ overnight. ${ }^{1} \mathrm{H}$ NMR $\left(500 \mathrm{MHz}, \mathrm{DMSO}_{6}\right) \delta 10.04$ (br, 2H), 8.38 (br, 2H), 8.23 (br, $\left.2 \mathrm{H}\right), 8.05$ (br, 2H), 7.99-7.93 (m, 6H), 7.86-7.82 (br, 2H), 7.80-7.74 (br, 4H), 7.62 (br, 4H), 5.54 (br, 4H).

\subsubsection{Synthesis of [6FDA I3A mXy][Tf $\left.{ }_{2} \mathrm{~N}\right]$}

The meta- derivative was synthesized via a similar procedure. 6FDA-I3A (6.00 g, $8.26 \mathrm{mmol})$ and mDCXy $(1.45 \mathrm{~g}, 8.26 \mathrm{mmol})$ were added with $80 \mathrm{~mL}$ of anhydrous DMF to a round-bottom heavy-walled pressure vessel and was sealed. The reaction was heated to $120^{\circ} \mathrm{C}$ for $24 \mathrm{~h}$. The product (as $\mathrm{Cl}^{-}$salt) was precipitated in an Erlenmeyer flask containing $400 \mathrm{~mL}$ of DI water with 3 eq. of LiTf $2 \mathrm{~N}$ $(7.12 \mathrm{~g}, 24.8 \mathrm{mmol})$. The [6FDA I3A $\mathrm{mXy}$ ] ionene solution was stirred for $24 \mathrm{~h}$ to allow for the anion exchange. The product was then filtered and dried in a vacuum oven at $120{ }^{\circ} \mathrm{C}$ overnight. ${ }^{1} \mathrm{H}$ NMR $\left(500 \mathrm{MHz}, \mathrm{DMSO}-d_{6}\right) \delta 10.04(\mathrm{~s}, 2 \mathrm{H}), 8.32(\mathrm{~s}, 2 \mathrm{H}), 8.25(\mathrm{~d}, J=8.0 \mathrm{~Hz}, 2 \mathrm{H}), 8.05(\mathrm{~s}, 2 \mathrm{H}), 8.03-7.90(\mathrm{~m}, 6 \mathrm{H})$, $7.90-7.83(\mathrm{~m}, 4 \mathrm{H}), 7.73(\mathrm{~s}, 1 \mathrm{H}), 7.71(\mathrm{~d}, J=7.3 \mathrm{~Hz}, 2 \mathrm{H}), 7.54(\mathrm{~m}, 3 \mathrm{H}), 5.56(\mathrm{~s}, 4 \mathrm{H})$.

\subsubsection{Synthesis of [6FDA I2A oXy][Tf $2 \mathrm{~N}]$}

The ortho- derivative was synthesized via a similar procedure. 6FDA-I2A (6.00 g, $8.26 \mathrm{mmol})$ and oDCXy $(1.45 \mathrm{~g}, 8.26 \mathrm{mmol})$ were added with $80 \mathrm{~mL}$ of anhydrous DMF to a round-bottom heavy-walled pressure vessel and was sealed. The reaction was heated to $120{ }^{\circ} \mathrm{C}$ for $24 \mathrm{~h}$. The product $\left(\mathrm{Cl}^{-}\right.$salt $)$ was precipitated in an Erlenmeyer flask containing $400 \mathrm{~mL}$ of DI water with 3 eq. of LiTf ${ }_{2} \mathrm{~N}(7.12 \mathrm{~g}$, $24.8 \mathrm{mmol}$ ). The [6FDA I2A oXy] ionene solution was stirred for $24 \mathrm{~h}$ to allow for the anion exchange. The product was then filtered and dried in a vacuum oven at $120{ }^{\circ} \mathrm{C}$ overnight. ${ }^{1} \mathrm{H} \mathrm{NMR}(500 \mathrm{MHz}$, DMSO- $\left.d_{6}\right) \delta 9.59(\mathrm{~s}, 2 \mathrm{H}), 8.87(\mathrm{dd}, J=14.5,6.9 \mathrm{~Hz}, 2 \mathrm{H}), 8.44(\mathrm{~m}, 4 \mathrm{H}), 8.14-8.04(\mathrm{~m}, 4 \mathrm{H}), 8.01(\mathrm{~m}, 2 \mathrm{H})$, $7.96(\mathrm{~s}, 2 \mathrm{H}), 7.85-7.76(\mathrm{~m}, 4 \mathrm{H}), 7.76-7.68(\mathrm{~m}, 4 \mathrm{H}), 4.85(\mathrm{~s}, 4 \mathrm{H})$.

\subsection{Preparation of Ionic Liquids}

The synthesis of 3-ethyl-1-methyl-1H-imidazol-3-ium bis((trifluoromethyl) sulfonyl)amide $\left(\left[\mathrm{C}_{2} \mathrm{mim}\right]\left[\mathrm{Tf}_{2} \mathrm{~N}\right]\right)$, 3-butyl-1-methyl-1H-imidazol-3-ium bis((trifluoromethyl) sulfonyl)amide $\left(\left[\mathrm{C}_{4} \mathrm{mim}\right]\left[\mathrm{Tf}_{2} \mathrm{~N}\right]\right)$, and 3-butyl-1-methyl-1H-imidazol-3-ium bis((trifluoromethyl) sulfonyl)amide $\left([\mathrm{Bnmim}]\left[\mathrm{Tf}_{2} \mathrm{~N}\right]\right)$ followed procedures previously introduced in the literature [24]. The ionic liquids shown in Figure 1 were incorporated as discussed in the following section on membrane formation.

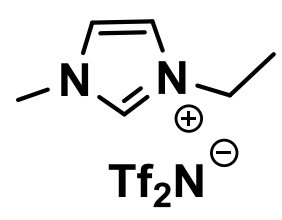

$\left[\mathrm{C}_{2} \operatorname{mim}\right]\left[T f_{2} \mathrm{~N}\right]$

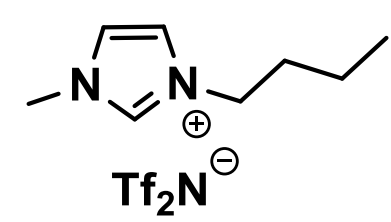

$\left[\mathrm{C}_{4} \operatorname{mim}\right]\left[\mathrm{Tf}_{2} \mathrm{~N}\right]$

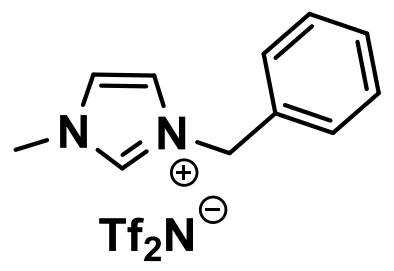

[Bnmim][Tf $\left.{ }_{2} \mathrm{~N}\right]$

Figure 1. $[\mathrm{Rmim}]\left[\mathrm{Tf}_{2} \mathrm{~N}\right]$ ionic liquids (ILs) utilized to form polyimide-ionene + IL composites.

\subsection{Membrane Preparation}

All the neat PI-ionenes and PI-ionene + IL membranes were prepared from solution-casting in N,N-dimethylacetamide (DMAc). As depicted in Table 1, the composite PI-ionene + IL membranes were prepared by combining two different equimolar ratios of the ILs with respective PI-ionenes. The membranes were fabricated as follows: the PI-ionenes were added to $15 \mathrm{~mL}$ centrifuge tubes, 
followed by the addition of the corresponding amount of an IL. DMAc was then added to bring the total volume to $9 \mathrm{~mL}$ for the composites and $7.5 \mathrm{~mL}$ for the neat dope solutions. The tubes were placed in a hot water bath for $2 \mathrm{~h}$, to promote the dissolution and distribution of the solute. The tubes were then centrifuged for $5 \mathrm{~min}$ at $6000 \mathrm{rpm}$ to separate any undissolved solids. The solution was then poured into (diameter $=60 \mathrm{~mm}$ ) wells in a Teflon mold. The molds were then heated to $40{ }^{\circ} \mathrm{C}$ in a vacuum oven for $24 \mathrm{~h}$. The temperature was slowly raised to $65,85^{\circ} \mathrm{C}$, and then $110^{\circ} \mathrm{C}$ over the course of $72 \mathrm{~h}$ in order to remove the solvent. The films were then peeled from the wells or collected into small discs of homogenized material. For uniformity, the membranes were then melt-pressed on a Carver press between sheets of Teflon, with the plate temperatures ranging from $75-90{ }^{\circ} \mathrm{C}$ under minimal pressure. The film thickness was controlled to be $\sim 90-120 \mu \mathrm{m}$ by adjusting the casting solution concentration.

Table 1. Mass/Ratio calculations for the membrane fabrications.

\begin{tabular}{|c|c|c|c|c|c|}
\hline \multicolumn{3}{|c|}{ Materials } & \multicolumn{3}{|c|}{ Mass/Ratios } \\
\hline ID & Polyimide-Ionene & IL (Equivalents) & Polyimide-Ionene [g] & IL $[g]$ & $\mathrm{V}_{\text {total }} \mathrm{w} /$ Solvent $[\mathrm{mL}]$ \\
\hline 1 & \multirow{6}{*}{$\begin{array}{l}\text { [6FDA I4A } \\
\mathrm{pXy}]\left[\mathrm{Tf}_{2} \mathrm{~N}\right]\end{array}$} & Neat & 0.75 & - & 7.5 \\
\hline 2 & & {$\left[\mathrm{C}_{2} \operatorname{mim}\right]\left[\mathrm{Tf}_{2} \mathrm{~N}\right](1)$} & 0.50 & 0.141 & 9 \\
\hline 3 & & {$\left[\mathrm{C}_{2} \operatorname{mim}\right]\left[\mathrm{Tf}_{2} \mathrm{~N}\right](2)$} & 0.50 & 0.281 & 9 \\
\hline 4 & & {$\left[\mathrm{C}_{4} \operatorname{mim}\right]\left[\mathrm{Tf}_{2} \mathrm{~N}\right](1)$} & 0.50 & 0.151 & 9 \\
\hline 5 & & {$\left[\mathrm{C}_{4} \mathrm{mim}\right]\left[\mathrm{Tf}_{2} \mathrm{~N}\right](2)$} & 0.50 & 0.301 & 9 \\
\hline 6 & & {$[\mathrm{Bnmim}]\left[\mathrm{Tf}_{2} \mathrm{~N}\right](2)$} & 0.50 & 0.326 & 9 \\
\hline 7 & \multirow{4}{*}{ 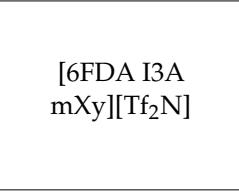 } & Neat & 0.75 & - & 7.5 \\
\hline 8 & & {$\left[\mathrm{C}_{2} \mathrm{mim}\right]\left[\mathrm{Tf}_{2} \mathrm{~N}\right](2)$} & 0.50 & 0.281 & 9 \\
\hline 9 & & {$\left[\mathrm{C}_{4} \operatorname{mim}\right]\left[\mathrm{Tf}_{2} \mathrm{~N}\right](2)$} & 0.50 & 0.301 & 9 \\
\hline 10 & & {$[\mathrm{Bnmim}]\left[\mathrm{Tf}_{2} \mathrm{~N}\right](2)$} & 0.50 & 0.326 & 9 \\
\hline 11 & \multirow{4}{*}{$\begin{array}{l}\text { [6FDA I2A } \\
\left.\text { oXy][Tf }{ }_{2} \mathrm{~N}\right]\end{array}$} & Neat & 0.75 & - & 7.5 \\
\hline 12 & & {$\left[\mathrm{C}_{2} \operatorname{mim}\right]\left[\mathrm{Tf}_{2} \mathrm{~N}\right](2)$} & 0.50 & 0.281 & 9 \\
\hline 13 & & {$\left[\mathrm{C}_{4} \mathrm{mim}\right]\left[\mathrm{Tf}_{2} \mathrm{~N}\right](2)$} & 0.50 & 0.301 & 9 \\
\hline 14 & & {$[$ Bnmim $]\left[\mathrm{Tf}_{2} \mathrm{~N}\right](2)$} & 0.50 & 0.326 & 9 \\
\hline
\end{tabular}

\subsection{Gas Separation Measurements}

The gas permeation behaviors of newly developed PI-ionenes and PI-ionene + IL membranes were studied using a high-vacuum time lag apparatus based on the constant-volume/variable pressure method, as described in our previous work [34-36]. In this study, all measurements were ideal (i.e., single-gas) and performed at $20^{\circ} \mathrm{C}$, and the feed pressure was $\sim 2 \mathrm{~atm}(\sim 30$ psia) against initial downstream vacuum (<0.01 psia). Membranes were "masked" on both sides using an adhesive aluminum tape in order to confine gas permeation through a fixed membrane area either of $3 / 8^{\prime \prime}$ or $1 / 2$ " diameter [37]. Gases were tested in the order of $\mathrm{N}_{2}, \mathrm{CH}_{4}$, and $\mathrm{CO}_{2}$. The membrane sample was carefully evacuated before each cycle of gas permeation tests in order to remove any residual dissolved gas species. The permeability coefficient was determined from the linear slope of the downstream pressure rise versus the time plot $(\mathrm{dp} / \mathrm{d} t)$ according to the following equation:

$$
P=\frac{273}{76} \times \frac{V l}{A T p_{o}} \times \frac{d p}{d t}
$$

where $P$ is the permeability expressed in Barrer $\left(1\right.$ barrer $=10^{-10}\left(\mathrm{~cm}^{3} \mathrm{STP} \mathrm{cm}\right) /\left(\mathrm{cm}^{2} \mathrm{~s} \mathrm{cmHg}\right) ; V\left(\mathrm{~cm}^{3}\right)$ is the downstream volume; $l(\mathrm{~cm})$ is the membrane thickness; $A\left(\mathrm{~cm}^{2}\right)$ is the effective area of the membrane; $T(\mathrm{~K})$ is the temperature of measurement; $p_{o}$ (Torr) is the pressure of the feed gas in the upstream chamber, and $\mathrm{d} p / \mathrm{d} t$ is the rate of the pressure rise under steady state. For a given gas pair (e.g., $\mathrm{i} / \mathrm{j})$, the permselectivity $(\alpha \mathrm{i}, \mathrm{j})$ was calculated as $\mathrm{Pi} / \mathrm{Pj}$ from the pure-gas permeability. 


\section{Results and Discussion}

\subsection{Characterization}

The purity, molecular structure, and thermophysical properties of both the neat PI-ionenes and composites with ILs were thoroughly investigated. ${ }^{1} \mathrm{H}-\mathrm{NMR}$ and ${ }^{13} \mathrm{C}-\mathrm{NMR}$ were utilized for structural confirmation of the monomers and polyimide-ionenes. NMR chemical shifts $[\delta]$ are reported in the experimental section, with spectra included in Figures S1-S6. ${ }^{1} \mathrm{H}-\mathrm{NMR}$ of the monomers supports formation of bis-imidazole imide monomers, indicated by the disappearance of the broad $\mathrm{NH}_{2}$ peak and a downfield shift of all peaks in the aromatic region as a result of imidization. Additionally, the chemical shifts between 9.59-10.04 ppm exhibited by the PI-ionenes are characteristic of imidazolium protons, indicating successful formation of imidazolium moieties upon polymerization via the Menshutkin reaction.

The structures of each PI-ionene, neat and with ILs, were further confirmed by FT-IR data (See Figure S7). All derivatives support the incorporation of the $\mathrm{Tf}_{2} \mathrm{~N}^{-}$anion $\left(\mathrm{SO}_{2}\right.$ stretching vibrations at 1180 and $1050 \mathrm{~cm}^{-1}$, SNS stretching at $725 \mathrm{~cm}^{-1}, \mathrm{CF}_{3}$ stretching at $1370 \mathrm{~cm}^{-1}$ ), incorporated in the backbone of the neat polymers and the counter ion of all three imidazolium ionic liquids [33,38]. $\mathrm{C}-\mathrm{H}$ stretching is observed, intensified by the incorporation of $\mathrm{C}_{2} \mathrm{mim}, \mathrm{C}_{4} \mathrm{mim}$, and Bnmim. Peaks corresponding to the imide functionality are observed by $\mathrm{C}-\mathrm{N}$ stretching around $1350 \mathrm{~cm}^{-1}$ and $\mathrm{C}=\mathrm{O}$ stretching at $1720 \mathrm{~cm}^{-1}$.

\subsection{Thermal Characterization}

Differential scanning calorimetry (DSC) was utilized to determine $\mathrm{T}_{\mathrm{g}}$ values for the three PI-ionenes and aforementioned IL hybrids. The thermal data are summarized in Table 2, with plots included in a supporting document (See Figure S8-S21). The $d$-spacing values for all derivatives are also summarized in Table 2, and discussed later in Section 3.3. The effects of the substitution pattern (i.e., para-, meta-, ortho connectivity) and IL content were studied. The [6FDA I4A pXy][Tf $2 \mathrm{~N}]$ polymer exhibited the lowest $\mathrm{T}_{\mathrm{g}}$ of the neat derivatives, while the $\mathrm{T}_{\mathrm{g}}$ of [6FDA I3A $\left.\mathrm{mXy}\right]\left[\mathrm{Tf}{ }_{2} \mathrm{~N}\right]$ was the highest. Due to its symmetric nature, the para-derivatives had the lowest $\mathrm{T}_{\mathrm{g}}$ values indicating better chain mobility. The inherent kinks of the meta- derivatives may promote better chain entanglement. The orthoderivatives were all very brittle, even at elevated temperatures and with IL, and showed the highest $\mathrm{T}_{\mathrm{g}}$ values. This may be attributed to poor chain entanglement and mobility due to the sterically strained linkages. Generally, the incorporation of 1 eq. of IL per polymer repeat unit lowered the $\mathrm{T}_{\mathrm{g}}$, in comparison to the neat material. However, when comparing derivatives $\mathbf{2 , 3}$ and $\mathbf{4 , 5}$, the $\mathrm{T}_{\mathrm{g}}$ observed is higher in hybrids containing 2 eq. of IL versus 1 eq. The stoichiometric pairing of 2 eq. of imidazolium IL with each repeat unit (containing two imidazolium groups along the backbone) seems to stabilize the material due to interactions between the ionic groups serving as a non-covalent "crosslink". There is no consistent trend correlating the effect of IL structure to $\mathrm{T}_{\mathrm{g}}$, but with [6FDA I4A pXy] $\left[\mathrm{Tf}_{2} \mathrm{~N}\right]+\mathrm{IL}$ hybrids increasing $\mathrm{T}_{\mathrm{g}}$ corresponds to $\mathrm{C}_{4} \mathrm{mim}<\mathrm{C}_{2} \mathrm{mim}<$ Bnmim. The aliphatic portion of $\mathrm{C}_{2}$ mim and $\mathrm{C}_{4}$ mim may allow for greater mobility between or amongst chains than the aromatic counterpart Bnmim. These glass transitions occur in comparable temperature ranges as partially aromatic PIs and similar ionic materials, yet the $\mathrm{T}_{\mathrm{g}}$ values of these PI-ionene composites are higher than many ionic liquid-based materials due to the incorporation of the imide linkages and aromatic content $[3,15,32,39-41]$. In comparison to rigid, 6FDA-based polyimide materials with no ionic content, the $\mathrm{T}_{\mathrm{g}}$ values are markedly lower, which may aid in processability $[11,14,42,43]$. 
Table 2. Glass transition and $d$-spacing values that characterize 6FDA polyimide-ionenes and their composites with IL.

\begin{tabular}{|c|c|c|c|c|}
\hline ID & Polyimide-Ionene & IL (Equivalents) & $\operatorname{Tg}\left[{ }^{\circ} \mathrm{C}\right]$ & $d$-spacing [̊̊] \\
\hline 1 & \multirow{6}{*}{$\begin{array}{l}\text { [6FDA I4A } \\
\left.p X_{y}\right]\left[\mathrm{Tf}_{2} \mathrm{~N}\right]\end{array}$} & Neat & 205.9 & 4.61 \\
\hline 2 & & {$\left[\mathrm{C}_{2} \operatorname{mim}\right]\left[\mathrm{Tf}_{2} \mathrm{~N}\right](1)$} & 199.4 & 4.55 \\
\hline 3 & & {$\left[\mathrm{C}_{2} \operatorname{mim}\right]\left[\mathrm{Tf}_{2} \mathrm{~N}\right](2)$} & 209.9 & 3.92 \\
\hline 4 & & {$\left[\mathrm{C}_{4} \operatorname{mim}\right]\left[\mathrm{Tf}_{2} \mathrm{~N}\right](1)$} & 182.4 & 4.83 \\
\hline 5 & & {$\left[\mathrm{C}_{4} \operatorname{mim}\right]\left[\mathrm{Tf}_{2} \mathrm{~N}\right](2)$} & 185.2 & 4.33 \\
\hline 6 & & {$[\mathrm{Bnmim}]\left[\mathrm{Tf}_{2} \mathrm{~N}\right](2)$} & 218.9 & 4.73 \\
\hline 7 & \multirow{4}{*}{$\begin{array}{l}\text { [6FDA I3A } \\
\text { mXy][Tf } 2 \mathrm{~N}]\end{array}$} & Neat & 236.2 & 4.66 \\
\hline 8 & & {$\left[\mathrm{C}_{2} \operatorname{mim}\right]\left[\mathrm{Tf}_{2} \mathrm{~N}\right](2)$} & 219.7 & 4.12 \\
\hline 9 & & {$\left[\mathrm{C}_{4} \mathrm{mim}\right]\left[\mathrm{Tf}_{2} \mathrm{~N}\right](2)$} & 199.2 & 4.24 \\
\hline 10 & & {$[\mathrm{Bnmim}]\left[\mathrm{Tf}_{2} \mathrm{~N}\right](2)$} & 185.5 & 4.11 \\
\hline 11 & \multirow{4}{*}{$\begin{array}{l}{\left[6 \mathrm{FDA} \mathrm{I}_{2} \mathrm{~A}\right.} \\
\mathrm{oXy}]\left[\mathrm{Tf}_{2} \mathrm{~N}\right]\end{array}$} & Neat & 221.8 & 4.61 \\
\hline 12 & & {$\left[\mathrm{C}_{2} \operatorname{mim}\right]\left[\mathrm{Tf}_{2} \mathrm{~N}\right](2)$} & 221.4 & 4.55 \\
\hline 13 & & {$\left[\mathrm{C}_{4} \mathrm{mim}\right]\left[\mathrm{Tf}_{2} \mathrm{~N}\right](2)$} & 243.3 & 4.35 \\
\hline 14 & & {$[\mathrm{Bnmim}]\left[\mathrm{Tf}_{2} \mathrm{~N}\right](2)$} & 236.3 & 4.26 \\
\hline
\end{tabular}

The effects of backbone connectivity and interactions with ILs can also be seen in the TGA data shown in Figure 2. [6FDA I2A oXy][Tf $\left.{ }_{2} \mathrm{~N}\right]$ (11) exhibited poor thermal stability overall, with the earliest onset of degradation. Some of the early mass lost is most likely due to trapped $\mathrm{H}_{2} \mathrm{O}$ and DMF; however, the steric strain and poor chain entanglement of the ortho-substitution propagating along the ionene backbone results in gradual degradation at elevated temperatures $\left(T_{d, 10 \%}=204{ }^{\circ} \mathrm{C}\right.$, $\mathrm{T}_{\mathrm{d}, 25 \%}=443^{\circ} \mathrm{C}$ ). [6FDA I3A $\left.\mathrm{mXy}\right]\left[\mathrm{Tf}_{2} \mathrm{~N}\right](7)$ showed improved stability, with a small loss from solvent and polymer mass around $217^{\circ} \mathrm{C}$ followed by a more significant onset of degradation around $416^{\circ} \mathrm{C}$ $\left(\mathrm{T}_{\mathrm{d}, 10 \%}=283{ }^{\circ} \mathrm{C}, \mathrm{T}_{\mathrm{d}, 25 \%}=456^{\circ} \mathrm{C}\right)$. The highest onset of degradation was observed in the [6FDA I4A $\mathrm{mXy}]\left[\mathrm{Tf}_{2} \mathrm{~N}\right]$ derivatives, even with IL present in the composite material. Neat [6FDA I4A pXy][Tf $2 \mathrm{~N}$ ] (1) was stable until $415{ }^{\circ} \mathrm{C}$, followed by a steady decline in mass $\left(\mathrm{T}_{\mathrm{d}, 10 \%}=283{ }^{\circ} \mathrm{C}, \mathrm{T}_{\mathrm{d}, 25 \%}=456{ }^{\circ} \mathrm{C}\right)$. TGA data supported the integration of IL into the PI-ionenes, with 1-2 eq. of $\mathrm{C}_{2}$ mim with [6FDA I4A pXy][Tf $\left.{ }_{2} \mathrm{~N}\right](2,3)$ stabilizing the material up to $375^{\circ} \mathrm{C}$. The stoichiometric pairing of 2 eq. of IL versus 1 eq. with the same backbone results in the onset of degradation to slightly higher temperatures. Thus, the [6FDA I3A $\mathrm{mXy}]\left[\mathrm{Tf}_{2} \mathrm{~N}\right]$ ionenes are comparably stable with 1 eq. $\mathrm{C}_{2} \mathrm{mim}\left(\mathrm{T}_{\mathrm{d}, 10 \%}=393{ }^{\circ} \mathrm{C}\right.$, $\left.\mathrm{T}_{\mathrm{d}, 25 \%}=435^{\circ} \mathrm{C}\right)$ or 2 eq. $\mathrm{C}_{2} \mathrm{mim}\left(\mathrm{T}_{\mathrm{d}, 10 \%}=400{ }^{\circ} \mathrm{C}, \mathrm{T}_{\mathrm{d}, 25 \%}=434{ }^{\circ} \mathrm{C}\right)$. The inflection point observed upon $50 \%$ mass loss is indicative of the breakdown of the $\mathrm{Tf}_{2} \mathrm{~N}$ anion (contributes $\sim 60 \mathrm{wt} \%$ per repeat unit) initially, coinciding with the rapid decomposition of the backbone that follows. These materials exhibit excellent thermal stability for ionic polymers, with thermal decomposition behavior comparable to primarily aromatic polyimides [3]. The connectivity through the $\mathrm{N}$ atoms of the imidazolium segment and the $\mathrm{CH}_{2}$ groups incorporated within the xylyl linkage lower the stability of these materials if compared to wholly aromatic, rigid PIs. 


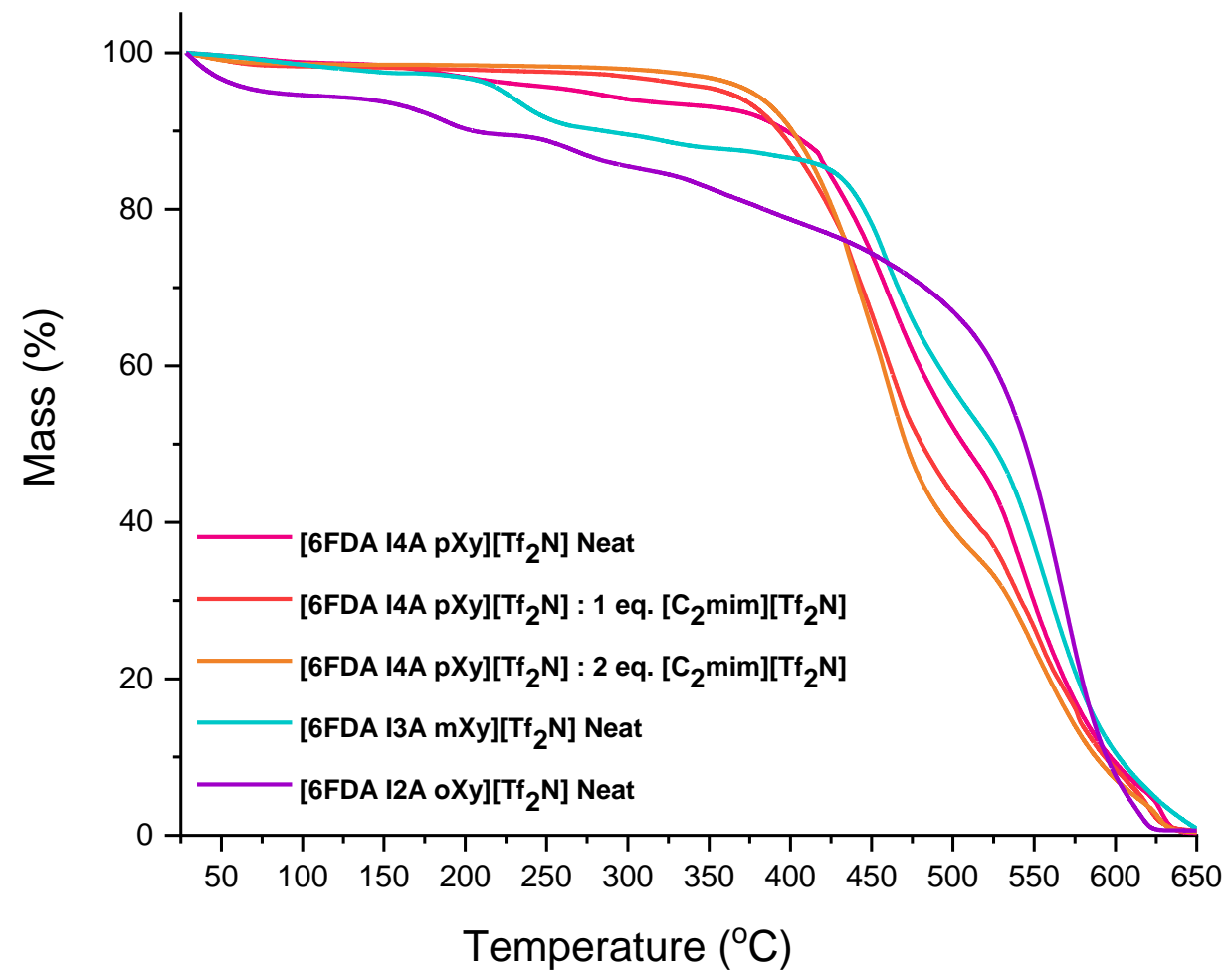

Figure 2. thermogravimetric analysis (TGA) data for polyimide-ionene derivatives, neat or with specified IL content.

\subsection{Structural Characterization}

$M_{N}$ values of the three, neat polyimide-ionenes were determined using MALDI-TOF MS. The $M_{N}$ values obtained from the plots included in Figure 3 ranged from $44-59 \mathrm{kDa}$, which corresponds to the number average degree of polymerization values $\left(\mathrm{X}_{\mathrm{N}}\right)$ ranging from 30 to 45 repeat units. [6FDA I2A oXy][Tf $\left.f_{2} \mathrm{~N}\right]$ showed the lowest $\mathrm{M}_{\mathrm{N}}(\sim 44 \mathrm{kDa})$, with a significant portion of smaller oligomers due to the steric hinderance the ortho-substituted end groups in the monomer, dihalide linkage, and resultant polymer. The [6FDA I3A $\mathrm{mXy}]\left[\mathrm{Tf}_{2} \mathrm{~N}\right]$ and [6FDA I4A pXy][Tf $\left.\mathrm{F}_{2} \mathrm{~N}\right]$ materials proved to have higher molecular weights, with $\mathrm{M}_{\mathrm{N}}$ values of $\sim 46 \mathrm{kDa}$ and $\sim 59 \mathrm{kDa}$, respectively. The presence of oligomeric and low molecular weight content in the meta- and ortho- derivatives may be caused by decreased structural stability promoting fragmentation upon ionization.

$\mathrm{X}$-ray diffraction (XRD) data were collected for all PI-ionene derivatives, to analyze the effects of backbone connectivity (i.e., para, meta, ortho-) and IL content on $d$-spacing. It has been shown that $d$-spacing can be correlated to interchain spacing in a polymeric network; thus, these trends indicate differences in the packing efficiency and are utilized here to predict which films would be expected to exhibit the highest permeability [44]. Figure 4 shows XRD spectra for the six [6FDA I4A $\mathrm{pXy}]\left[\mathrm{Tf}_{2} \mathrm{~N}\right]$ derivatives for comparison. The other materials were also tested, with $d$-spacing values included earlier in Table 2 (See Figure S23). Each showed similar broad halos, with the peak of the main halo appearing between $2 \theta=22^{\circ}-27^{\circ}$ and a secondary low-intensity halo spanning $2 \theta=36^{\circ}-67^{\circ}$. Bragg's law was used to determine $d$-spacing values, utilizing the Diffrac.Eva software for accuracy. Due to the similarity in the backbone structure, the $d$-spacing values fall within a small range of $3.92-4.83 \AA$ for the main halo. In most cases, the $d$-spacing decreases slightly with the incorporation of $\mathrm{IL}$, as these free imidazolium cations migrate and fill the space between the ionene chains. As seen in 2-5, the coordination between the backbone and the ILs is stronger with the pairing of 2 eq. of IL, with lower $d$-spacing values indicating that the chains are drawn closer around these ionic groups. The main halo is notably broadened (somewhat bimodal) by the incorporation of 2 eq. of IL, and the composite material is more rubbery or amorphous than the glassy neat polymers. The [6FDA I4A 
pXy][Tf $\left.{ }_{2} \mathrm{~N}\right]$ materials $1-6$ exhibit the highest $d$-spacing values, though comparable to the [6FDA I2A oXy $\left[\mathrm{Tf}_{2} \mathrm{~N}\right]$ materials 11-14.

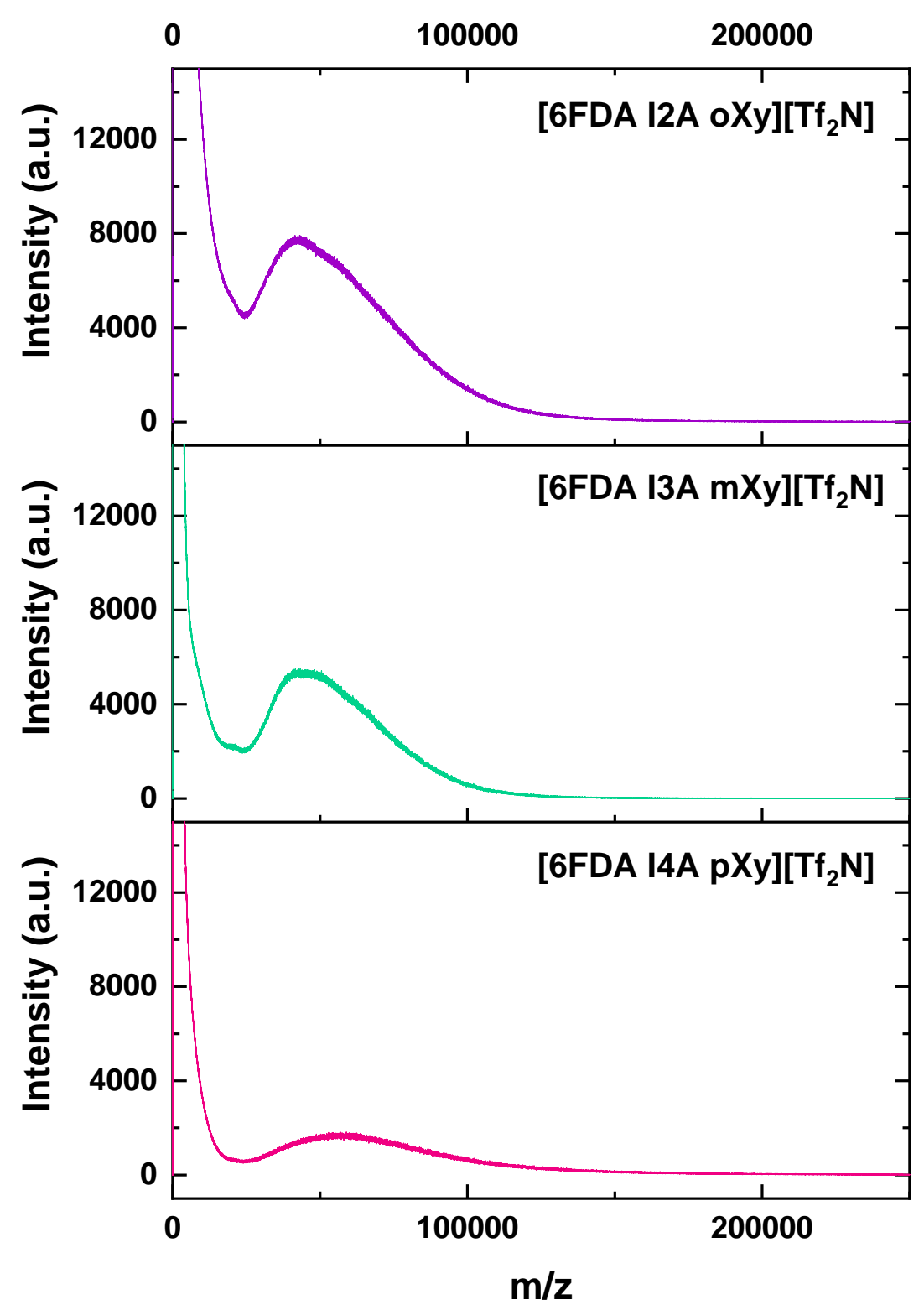

Figure 3. MALDI-TOF MS spectra for PI-ionenes.

These structure-property characterizations were evaluated in order to understand the suitability of these PI-ionene + IL hybrids as gas separation membranes. Although [6FDA I3A $\mathrm{mXy}]\left[\mathrm{Tf}_{2} \mathrm{~N}\right.$ ] and [6FDA I2A oXy][Tf $2 \mathrm{~N}$ ] ionenes and their associated composites with ILs showed good thermal resistance and moderate stability, the lower molecular weight caused the processed films to be less mechanically stable and not adequate for gas separation performance. Thus, only the [6FDA I4A $\mathrm{pXy}]\left[\mathrm{Tf}_{2} \mathrm{~N}\right]$ backbone was selected as the basis for comparison of permeability and selectivity in this newly developed PI-ionene series. It also should be mentioned that the stoichiometric pairing of 2 eq. of imidazolium ILs with each repeating unit of PI-ionene seemed more stable and tolerable as evidenced by DSC analysis. Therefore, [6FDA I4A pXy][Tf $2 \mathrm{~N}]$ ionene + IL composites having 2 eq. of imidazolium ILs were considered for further gas separation studies. 


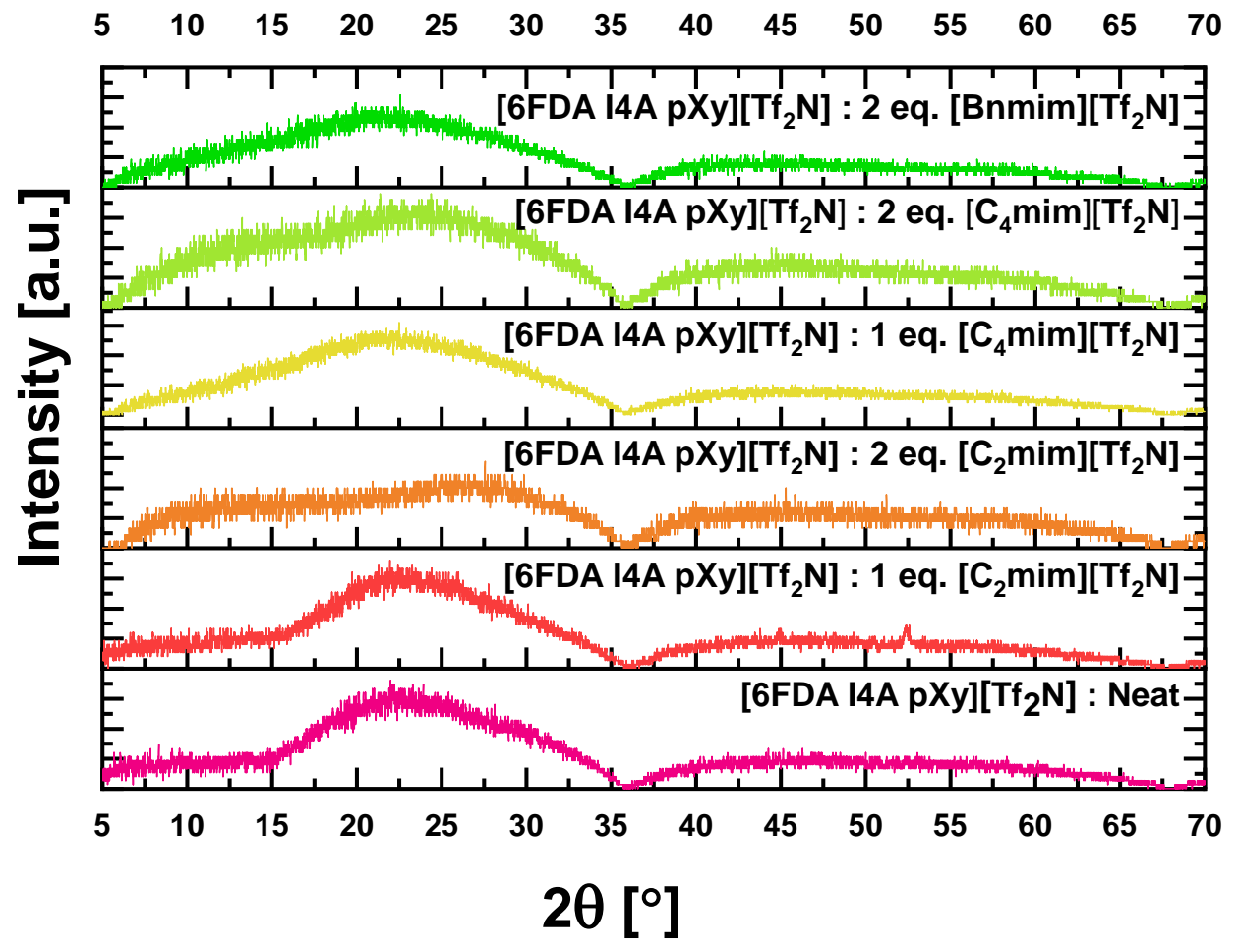

Figure 4. XRD profiles of the six [6FDA I4A pXy][Tf $2 \mathrm{~N}]$ derivatives.

\subsection{Gas Separation Performance}

Images of full films of two [6FDA I4A pXy][Tf $\left.{ }_{2} \mathrm{~N}\right]$ ionene + IL composites with 2 eq. of imidazolium ILs are included in Figure 5.

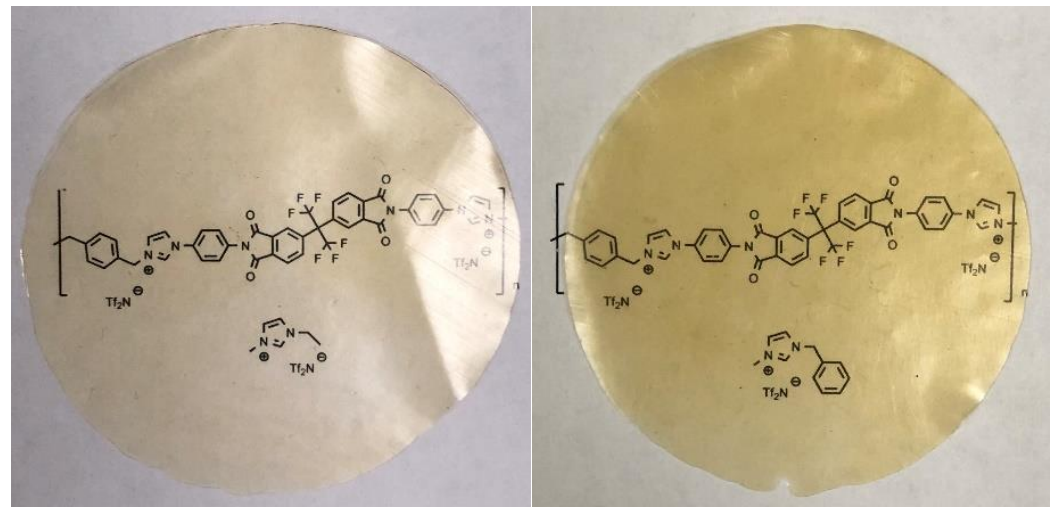

Figure 5. Membranes $\left(\sim 3^{\prime \prime}\right.$ in diameter) over their respective structures. [6FDA I4A pXy][Tf $f_{2} \mathrm{~N}$ ]: $\left[\mathrm{C}_{2} \mathrm{mim}\right]\left[\mathrm{Tf}_{2} \mathrm{~N}\right](\mathbf{l e f t})$ and [6FDA I4A pXy][Tf $\left.2 \mathrm{~N}\right]$ : [Bnmim][Tf $\left.2 \mathrm{~N}\right]$ (right).

The pure gas permeabilities and permselectivities of the [6FDA I4A pXy][Tf $\left.f_{2} \mathrm{~N}\right]$ ionene and IL-containing composites with $\left[\mathrm{C}_{2} \operatorname{mim}\right]\left[\mathrm{Tf}_{2} \mathrm{~N}\right],\left[\mathrm{C}_{4} \operatorname{mim}\right]\left[\mathrm{Tf}_{2} \mathrm{~N}\right]$ and $[\mathrm{Bnmim}]\left[\mathrm{Tf}_{2} \mathrm{~N}\right]$ were investigated using high-vacuum time-lag units at $3 \mathrm{~atm}$ and $20{ }^{\circ} \mathrm{C}$ (Table 3). However, the permeation results of [6FDA I4A pXy][Tf $\left.{ }_{2} \mathrm{~N}\right]$ composite membrane with $\left[\mathrm{C}_{2} \operatorname{mim}\right]\left[\mathrm{Tf}_{2} \mathrm{~N}\right]$ is not presented in Table 3 because of inconsistency in the measured values. The [6FDA I4A pXy][Tf $\left.{ }_{2} \mathrm{~N}\right]$ with 2 eq. of $\left[\mathrm{C}_{2} \mathrm{mim}\right]\left[\mathrm{Tf}_{2} \mathrm{~N}\right]$ was unstable under higher pressure, plausibly due to the extremely higher interchain packing (lowest $d$-spacing value of $3.92 \AA$ was obtained for this combination, Table 2). Nonetheless, the other two hybrid-ionene membranes containing $\mathrm{C}_{4} \mathrm{mim}$ and Bnmim ILs exhibited significant changes in the separation properties of $\mathrm{CO}_{2}$ relative to $\mathrm{N}_{2}$ and $\mathrm{CH}_{4}$. The high $\mathrm{CO}_{2} / \mathrm{CH}_{4}$ selectivities are comparable 
to values reported for leading gas separation membranes; however, a significant increase in the permeability $\left(10^{2}-10^{4}\right.$ barrer) would be required to compete with membranes at or over the Robeson Upper Bound [45].

Table 3. Pure Gas Permeabilities $(P)^{\mathrm{a}}$ and Permselectivities $(\alpha)$ for the neat [6FDA I4A pXy][Tf $\left.{ }_{2} \mathrm{~N}\right]$ ionene and composite membranes with $\left[\mathrm{C}_{4} \operatorname{mim}\right]\left[\mathrm{Tf}_{2} \mathrm{~N}\right]$ and $[\mathrm{Bnmim}]\left[\mathrm{Tf}_{2} \mathrm{~N}\right]$ at 3 atm and $20{ }^{\circ} \mathrm{C}$.

\begin{tabular}{|c|c|c|c|c|c|}
\hline$[6 F D A ~ I 4 A ~ p X y]\left[T f_{2} N\right]$ & $P_{\mathrm{CO} 2}$ & $P_{\mathrm{N} 2}$ & $P_{\mathrm{CH} 4}$ & $\alpha_{\mathrm{CO} 2 / \mathrm{N} 2}$ & $\alpha_{\mathrm{CO} 2 / \mathrm{CH} 4}$ \\
\hline Neat & $2.15 \pm 0.16$ & $0.103 \pm 0.01$ & $0.161 \pm 0.02$ & $20.9 \pm 2$ & $13.4 \pm 1$ \\
\hline$\left[\mathrm{C}_{4} \mathrm{mim}\right]\left[\mathrm{Tf}_{2} \mathrm{~N}\right]$ (2 equiv.) & $4.57 \pm 0.30$ & $0.239 \pm 0.02$ & $0.189 \pm 0.02$ & $19.1 \pm 1$ & $24.8 \pm 2$ \\
\hline$[\mathrm{Bnmim}]\left[\mathrm{Tf}_{2} \mathrm{~N}\right]$ (2 equiv.) & $6.32 \pm 0.15$ & $0.282 \pm 0.02$ & $0.294 \pm 0.02$ & $22.4 \pm 1$ & $21.5 \pm 1$ \\
\hline
\end{tabular}

As shown in Table 3, both the $\left[\mathrm{C}_{4} \mathrm{mim}\right]\left[\mathrm{Tf}_{2} \mathrm{~N}\right]$ and $[\mathrm{Bnmim}]\left[\mathrm{Tf}_{2} \mathrm{~N}\right]$ composites of [6FDA I4A pXy] $\left[\mathrm{Tf}_{2} \mathrm{~N}\right]$ displayed a drastic increase in the permeability of the $\mathrm{CO}_{2}$ compared to the neat [6FDA I4A pXy] $\left[\mathrm{Tf}_{2} \mathrm{~N}\right]$ membrane, probably due to the increased quadrupole interactions of ILs with $\mathrm{CO}_{2}$, as well as the versatility of the polymer matrix. The $\left[\mathrm{C}_{4} \mathrm{mim}\right]\left[\mathrm{Tf}_{2} \mathrm{~N}\right]$ composite membrane obtained a $\sim 2 \times$ increase ( 4.57 barrer) and the $[\mathrm{Bnmim}]\left[\mathrm{Tf}_{2} \mathrm{~N}\right]$ composite displayed nearly a $3 \times$ increase ( 6.32 barrer) in their $\mathrm{CO}_{2}$ permeabilities. Unlike the high $\mathrm{CO}_{2}$ separation trends, the ability of the [6FDA I4A pXy][Tf $\left.{ }_{2} \mathrm{~N}\right]+\mathrm{IL}$ composites to separate other nonpolar gases $\left(\mathrm{N}_{2}\right.$ and $\left.\mathrm{CH}_{4}\right)$, appeared to be normal, and these materials yielded enhanced $\mathrm{CO}_{2}$ permeability without sacrificing their $\mathrm{CO}_{2} / \mathrm{N}_{2}$ and $\mathrm{CO}_{2} / \mathrm{CH}_{4}$ permselectivities (Table 3). Overall, the $\mathrm{CO}_{2}$ separation behaviors of both the $\mathrm{C}_{4} \mathrm{mim}$ and Bnmim containing hybrid membranes of newly developed [6FDA I4A pXy][Tf $f_{2} \mathrm{~N}$ ] ionene exhibited potential usefulness for $\mathrm{CO}_{2} /$ light gas separation in the context of an appropriate structural and stoichiometric design.

\section{Conclusions}

In conclusion, a series of three 6FDA-based PI-ionenes and composites with ILs have been successfully synthesized, and structure-property relationships of substitution patterns with para-, meta-, and ortho connectivity, as well as the utility of the corresponding membranes for $\mathrm{CO}_{2}$ gas separation as neat ionene and IL hybrids forms were studied. The results showed that the newly developed 6FDA-based polyimide-ionenes were compatible with the ILs such as $\left[\mathrm{C}_{2} \operatorname{mim}\right]\left[\mathrm{Tf}_{2} \mathrm{~N}\right],\left[\mathrm{C}_{4} \mathrm{mim}\right]\left[\mathrm{Tf}_{2} \mathrm{~N}\right]$ and $[\mathrm{Bnmim}]\left[\mathrm{Tf}_{2} \mathrm{~N}\right]$, producing homogeneous hybrid membranes with the high thermal stability of $\sim 380^{\circ} \mathrm{C}$. Specifically, [6FDA I4A pXy] $\left[\mathrm{Tf}_{2} \mathrm{~N}\right]$ ionene $+\mathrm{IL}$ composites showed promising performance for membrane-based $\mathrm{CO}_{2}$ separation with increased permeability of $2 \times$ and $3 \times$ for the $\left[\mathrm{C}_{4} \mathrm{mim}\right]\left[\mathrm{Tf}_{2} \mathrm{~N}\right]$ and $[\mathrm{Bnmim}]\left[\mathrm{Tf}_{2} \mathrm{~N}\right]$ composites, respectively, compared to the neat [6FDA I4A pXy][Tf $\left.{ }_{2} \mathrm{~N}\right]$. The feasibility of using 6FDA-based PI-ionenes in combination with stable films composed of various ILs, which display a high affinity toward $\mathrm{CO}_{2}$, may enable the development of materials with a range of properties. Furthermore, in view of the versatility and functionality of the imidazolium platform, together with the ability to tune the structural-property relationships, PI-ionenes can be further developed for use in gas separation membranes.

Supplementary Materials: The following are available online at http://www.mdpi.com/2077-0375/9/7/79/s1, Figure S1: ${ }^{1} \mathrm{H}-\mathrm{NMR}$ of I3A, S2: ${ }^{1} \mathrm{H}-\mathrm{NMR}$ of 6 FDA I3A monomer, S3: ${ }^{1} \mathrm{H}-\mathrm{NMR}$ of 6 FDA I2A monomer, S4: ${ }^{1} \mathrm{H}-\mathrm{NMR}$ of [6FDA I4A pXy][Tf ${ }_{2} \mathrm{~N}$ ] polyimide-ionene, S5: ${ }^{1} \mathrm{H}-\mathrm{NMR}$ of [6FDA I3A $\left.\mathrm{mXy}\right]\left[\mathrm{Tf}_{2} \mathrm{~N}\right]$ polyimide-ionene, S6: ${ }^{1} \mathrm{H}-\mathrm{NMR}$ of [6FDA I2A oXy][Tf ${ }_{2} \mathrm{~N}$ ] polyimide-ionene, S7: Compilation of IR spectra, S8: DSC plots for [6FDA I4A pXy][Tf $\left.f_{2} \mathrm{~N}\right]$ Neat, S9: DSC plots for [6FDA I4A pXy][Tf $\left.{ }_{2} \mathrm{~N}\right]: 1$ eq. [ $\left.\mathrm{C}_{2} \mathrm{mim}\right]\left[\mathrm{Tf}_{2} \mathrm{~N}\right.$ ], S10: DSC plots for [6FDA

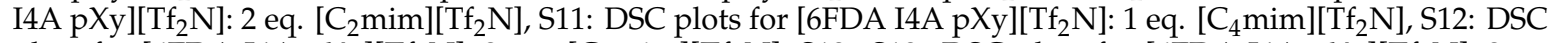
plots for [6FDA I4A pXy][Tf $\left.{ }_{2} \mathrm{~N}\right]: 2$ eq. $\left[\mathrm{C}_{4} \mathrm{mim}\right.$ ] $\left[\mathrm{Tf}_{2} \mathrm{~N}\right]$, S13: S13: DSC plots for [6FDA I4A pXy][Tf $\left.\mathrm{Tf}_{2} \mathrm{~N}\right]: 2$ eq. [Bnmim] $\left[\mathrm{Tf}_{2} \mathrm{~N}\right]$, S14: DSC plots for [6FDA I3A mXy][Tf $\left.{ }_{2} \mathrm{~N}\right]$ Neat, S15: DSC plots for [6FDA I3A mXy][Tf $\left.{ }_{2} \mathrm{~N}\right]: 2$ eq. $\left[\mathrm{C}_{2} \mathrm{mim}\right]\left[\mathrm{Tf}_{2} \mathrm{~N}\right], \mathrm{S} 16$ : DSC plots for [6FDA I3A mXy][Tf $\left.{ }_{2} \mathrm{~N}\right]: 2$ eq. $\left[\mathrm{C}_{4} \mathrm{mim}\right]\left[\mathrm{Tf}_{2} \mathrm{~N}\right]$, S17: DSC plots for [6FDA I3A $\mathrm{mXy}]\left[\mathrm{Tf}_{2} \mathrm{~N}\right]: 2$ eq. [Bnmim][Tf ${ }_{2} \mathrm{~N}$ ], S18: DSC plots for [6FDA I2A oXy][Tf ${ }_{2} \mathrm{~N}$ ] Neat, S19: DSC plots for [6FDA I2A oXy][Tf $\left.f_{2} \mathrm{~N}\right]: 2$ eq. [ $\left.\mathrm{C}_{2} \mathrm{mim}\right]\left[\mathrm{Tf}_{2} \mathrm{~N}\right]$, S20: DSC plots for [6FDA I2A oXy][Tf $\left.{ }_{2} \mathrm{~N}\right]: 2$ eq. [C $\left.\mathrm{C}_{4} \mathrm{mim}\right]\left[\mathrm{Tf}_{2} \mathrm{~N}\right]$, S21: DSC plots for [6FDA I2A oXy][Tf $2 \mathrm{~N}]: 2$ eq. [Bnmim] [Tf $\left.f_{2} \mathrm{~N}\right], \mathrm{S} 22$ : MALDI-TOF spectra for the three, neat polyimide-ionenes, 
S23: XRD spectra for all samples, with $2 \theta$ values from 5-70 ${ }^{\circ}, \mathrm{S} 24:$ SEM image of [6FDA I4A pXy][Tf $\left.{ }_{2} \mathrm{~N}\right]$ (Neat), S25: SEM image of [6FDA I4A pXy][Tf $\left.{ }_{2} \mathrm{~N}\right]:$ [ $\left.\mathrm{C}_{2} \mathrm{mim}\right]\left[\mathrm{Tf}_{2} \mathrm{~N}\right]$ (1 equivalent), S26: SEM image of [6FDA I4A pXy][Tf $\left.{ }_{2} \mathrm{~N}\right]:$ $\left[\mathrm{C}_{2} \mathrm{mim}\right]\left[\mathrm{Tf}_{2} \mathrm{~N}\right]$ (2 equivalents), S27: SEM image of [6FDA I4A pXy][Tf $\left.\mathrm{TH}_{2} \mathrm{~N}\right]$ : $\left[\mathrm{C}_{4} \mathrm{mim}\right]\left[\mathrm{Tf}_{2} \mathrm{~N}\right]$ (1 equivalent).

Author Contributions: Conceptualization-K.E.O. and J.E.B.; Methodology-K.E.O. and I.K.; Synthesis-K.E.O., E.M.D. and D.M.N.; Characterization-K.E.O., E.M.D. and D.M.N.; Membrane Fabrication-K.E.O. and I.K.; Data Curation, -K.E.O. and I.K.; Formal Analysis-K.E.O. and I.K.; Preparation of Figures-K.E.O.; Preparation of Tables-K.E.O. and I.K.; Thermal Analysis-E.M.J.; Resources-J.E.B. and E.M.J.; Writing-Original Draft Preparation, -K.E.O. and I.K.; Writing-Review \& Editing-K.E.O. and J.B; Supervision-J.E.B.; Project Administration- J.E.B.; Funding Acquisition-J.E.B.

Funding: This material is based upon work supported by the U.S. Department of Energy, Office of Science, Office of Basic Energy Sciences, Separation Science program under Award Number DE-SC0018181. Thermal characterizations were supported by a grant from NASA (CAN 80MSFC18M0041). Support from the National Science Foundation from the Major Research Instrumentation Program (CHE-1726812) for the purchase of the MALDI-TOF MS is gratefully acknowledged.

Acknowledgments: The authors acknowledge Rich Martens of the University of Alabama Central Analytical Facility for his assistance in obtaining the SEM images of the membranes.

Conflicts of Interest: The authors declare no conflict of interest.

\section{References}

1. Sroog, C.E. Polyimides. Prog. Polym. Sci. 1991, 16, 561-694. [CrossRef]

2. Xiao, Y.; Low, B.T.; Hosseini, S.S.; Chung, T.S.; Paul, D.R. The strategies of molecular architecture and modification of polyimide-based membranes for $\mathrm{CO}_{2}$ removal from natural gas-A review. Prog. Polym. Sci. 2009, 34, 561-580. [CrossRef]

3. Zhuang, Y.; Seong, J.G.; Lee, Y.M. Polyimides containing aliphatic/alicyclic segments in the main chains. Prog. Polym. Sci. 2019, 92, 35-88. [CrossRef]

4. Rozhanskiia, I.; Okuyama, K.; Gotoa, K. Synthesis and properties of polyimides derived from isomeric biphenyltetracarboxylic dianhydrides. Polymer 2000, 41, 7057-7065. [CrossRef]

5. Mi, Z.; Liu, Z.; Yao, J.; Wang, C.; Zhou, C.; Wang, D.; Zhao, X.; Zhou, H.; Zhang, Y.; Chen, C. Transparent and soluble polyimide films from 1,4:3,6-dianhydro-D-mannitol based dianhydride and diamines containing aromatic and semiaromatic units: Preparation, characterization, thermal and mechanical properties. Polym. Degrad. Stab. 2018, 151, 80-89. [CrossRef]

6. Chen, Y.-Y.; Yang, C.-P.; Hsiao, S.-H. Soluble and Colorless Poly(ether-imide)s Based on a Benzonorbornane Bis(ether anhydride) and Trifluoromethyl-Substituted Aromatic Bis(ether-amine)s. Macromol. Chem. Phys. 2006, 207, 1888-1898. [CrossRef]

7. Calle, M.; Lozano, A.n.E.; de La Campa, J.G.; de Abajo, J. Novel Aromatic Polyimides Derived from 5'-t-Butyl-2'-pivaloylimino-3,4,3' ${ }^{\prime \prime} 4^{\prime \prime}$-m-terphenyltetracarboxylic Dianhydride with Potential Application on Gas Separation Processes. Macromolecules 2010, 43, 2268-2275. [CrossRef]

8. Kammakakam, I.; Nam, S.; Kim, T.-H. PEG-imidazolium-functionalized 6FDA-durene polyimide as a novel polymeric membrane for enhanced $\mathrm{CO}_{2}$ separation. RSC Adv. 2016, 6, 31083-31091. [CrossRef]

9. Wiegand, J.R.; Smith, Z.P.; Liu, Q.; Patterson, C.T.; Freeman, B.D.; Guo, R. Synthesis and characterization of triptycene-based polyimides with tunable high fractional free volume for gas separation membranes. J. Mater. Chem. A 2014, 2, 13309-13320. [CrossRef]

10. Cho, Y.J.; Park, H.B. High Performance Polyimide with High Internal Free Volume Elements. Macromol. Rapid Commun. 2011, 32, 579-586. [CrossRef] [PubMed]

11. Qiu, W.; Chen, C.-C.; Kincer, M.R.; Koros, W.J. Thermal analysis and its application in evaluation of fluorinated polyimide membranes for gas separation. Polymer 2011, 52, 4073-4082. [CrossRef]

12. Zhang, M.; Deng, L.; Xiang, D.; Cao, B.; Hosseini, S.; Li, P. Approaches to Suppress CO2-Induced Plasticization of Polyimide Membranes in Gas Separation Applications. Processes 2019, 7. [CrossRef]

13. Kammakakam, I.; Nam, S.; Kim, T.-H. Ionic group-mediated crosslinked polyimide membranes for enhanced $\mathrm{CO}_{2}$ separation. RSC Adv. 2015, 5, 69907-69914. [CrossRef]

14. Qiu, W.; Xu, L.; Chen, C.-C.; Paul, D.R.; Koros, W.J. Gas separation performance of 6FDA-based polyimides with different chemical structures. Polymer 2013, 54, 6226-6235. [CrossRef]

15. Li, P.; Zhao, Q.; Anderson, J.L.; Varanasi, S.; Coleman, M.R. Synthesis of copolyimides based on room temperature ionic liquid diamines. J. Polym. Sci. Part. A Polym. Chem. 2010, 48, 4036-4046. [CrossRef] 
16. Li, P.; Coleman, M.R. Synthesis of room temperature ionic liquids based random copolyimides for gas separation applications. Eur. Polym. J. 2013, 49, 482-491. [CrossRef]

17. Wang, Z.; Wang, D.; Zhang, F.; Jin, J. Tröger's Base-Based Microporous Polyimide Membranes for High-Performance Gas Separation. ACS Macro Lett. 2014, 3, 597-601. [CrossRef]

18. Yoshino, M.; Ito, K.; KITA, H.; Okamoto, K.-I. Effects of Hard-Segment Polymers on CO2/N2 GasSeparation Properties of Poly(ethylene oxide)-Segmented Copolymers. J. Polym. Sci. Part. B Polym. Phys. 2000, 38, 1707-1715. [CrossRef]

19. Bates, E.D.; Mayton, R.D.; Ntai, I.; Davis, J.H. $\mathrm{CO}_{2}$ Capture by a Task-Specific Ionic Liquid. J. Am. Chem. Soc. 2002, 124, 926-927. [CrossRef]

20. Raeissi, S.; Peters, C.J. A potential ionic liquid for $\mathrm{CO}_{2}$-separating gas membranes: Selection and gas solubility studies. Green Chem. 2009, 11, 185-192. [CrossRef]

21. Cowan, M.G.; Masuda, M.; McDanel, W.M.; Kohno, Y.; Gin, D.L.; Noble, R.D. Phosphonium-based poly(Ionic liquid) membranes: The effect of cation alkyl chain length on light gas separation properties and Ionic conductivity. J. Membr. Sci. 2016, 498, 408-413. [CrossRef]

22. Domańska, U.; Pobudkowska, A.; Królikowski, M. Separation of aromatic hydrocarbons from alkanes using ammonium ionic liquid C2NTf2 at T=298.15K. Fluid Phase Equilib. 2007, 259, 173-179. [CrossRef]

23. Vollas, A.; Chouliaras, T.; Deimede, V.; Ioannides, T.; Kallitsis, J. New Pyridinium Type Poly(Ionic Liquids) as Membranes for CO(2) Separation. Polymers (Basel) 2018, 10. [CrossRef] [PubMed]

24. Bara, J.E.; Carlisle, T.K.; Gabriel, C.J.; Camper, D.; Finotello, A.; Gin, D.L.; Noble, R.D. Guide to CO2Separations in Imidazolium-Based Room-Temperature Ionic Liquids. Ind. Eng. Chem. Res. 2009, 48, 2739-2751. [CrossRef]

25. Anderson, E.B.; Long, T.E. Imidazole- and imidazolium-containing polymers for biology and material science applications. Polymer 2010, 51, 2447-2454. [CrossRef]

26. Lu, W.; Shao, Z.-G.; Zhang, G.; Zhao, Y.; Li, J.; Yi, B. Preparation and characterization of imidazoliumfunctionalized poly (ether sulfone) as anion exchange membrane and ionomer for fuel cell application. Int. J. Hydrogen Energy 2013, 38, 9285-9296. [CrossRef]

27. Kammakakam, I.; Kim, H.W.; Nam, S.; Park, H.B.; Kim, T.-H. Alkyl imidazolium-functionalized cardo-based poly(ether ketone)s as novel polymer membranes for $\mathrm{O}_{2} / \mathrm{N}_{2}$ and $\mathrm{CO}_{2} / \mathrm{N}_{2}$ separations. Polymer 2013, 54, 3534-3541. [CrossRef]

28. Gye, B.; Kammakakam, I.; You, H.; Nam, S.; Kim, T.-H. PEG-imidazolium-incorporated polyimides as high-performance $\mathrm{CO}_{2}$-selective polymer membranes: The effects of PEG-imidazolium content. Sep. Purif. Technol. 2017, 179, 283-290. [CrossRef]

29. Xu, Y.; Yang, J.; Ye, N.; Teng, M.; He, R. Modification of poly(aryl ether ketone) using imidazolium groups as both pendants and bridging joints for anion exchange membranes. Eur. Polym. J. 2015, 73, 116-126. [CrossRef]

30. Ohno, H. Design of Ion Conductive Polymers Based on Ionic Liquids. Macromol. Symp. 2007, 249-250, 551-556. [CrossRef]

31. Thankamony, R.L.; Chu, H.; Lim, S.; Yim, T.; Kim, Y.-J.; Kim, T.-H. Preparation and characterization of imidazolium-PEO-based Ionene/PVDF(HFP)/LiTFSI as a novel Gel polymer electrolyte. Macromol. Res. 2014, 23, 38-44. [CrossRef]

32. Bara, J.E.; O'Harra, K.E. Recent Advances in the Design of Ionenes: Toward Convergence with High-Performance Polymers. Macromol. Chem. Phys. 2019. [CrossRef]

33. O'Harra, K.E.; Kammakakam, I.; Bara, J.E.; Jackson, E.M. Understanding the effects of backbone chemistry and anion type on the structure and thermal behaviors of imidazolium polyimide-ionenes. Polym. Int. 2019. [CrossRef]

34. Kammakakam, I.; O’Harra, K.E.; Dennis, G.P.; Jackson, E.M.; Bara, J.E. Self-healing imidazolium-based ionene-polyamide membranes: An experimental study on physical and gas transport properties. Polym. Int. 2019. [CrossRef]

35. Kammakakam, I.; O’Harra, K.E.; Bara, J.E.; Jackson, E.M. Design and Synthesis of Imidazolium-Mediated Tröger's Base-Containing Ionene Polymers for Advanced $\mathrm{CO}_{2}$ Separation Membranes. ACS Omega 2019, 4, 3439-3448. [CrossRef]

36. Mittenthal, M.S.; Flowers, B.S.; Bara, J.E.; Whitley, J.W.; Spear, S.K.; Roveda, J.D.; Wallace, D.A.; Shannon, M.S.; Holler, R.; Martens, R.; et al. Ionic Polyimides: Hybrid Polymer Architectures and Composites with Ionic Liquids for Advanced Gas Separation Membranes. Ind. Eng. Chem. Res. 2017, 56, 5055-5069. [CrossRef] 
37. Li, P.; Paul, D.R.; Chung, T.-S. High performance membranes based on ionic liquid polymers for CO2 separation from the flue gas. Green Chem. 2012, 14. [CrossRef]

38. Paschoal, V.H.; Faria, L.F.O.; Ribeiro, M.C.C. Vibrational Spectroscopy of Ionic Liquids. Chem. Rev. 2017, 117, 7053-7112. [CrossRef]

39. Shaplov, A.S.; Morozova, S.M.; Lozinskaya, E.I.; Vlasov, P.S.; Gouveia, A.S.L.; Tomé, L.C.; Marrucho, I.M.; Vygodskii, Y.S. Turning into poly(ionic liquid)s as a tool for polyimide modification: Synthesis, characterization and $\mathrm{CO}_{2}$ separation properties. Polym. Chem. 2016, 7, 580-591. [CrossRef]

40. Zhang, C.; Cao, B.; Coleman, M.R.; Li, P. Gas transport properties in (6FDA-RTIL)-(6FDA-MDA) block copolyimides. J. Appl. Polym. Sci. 2016, 133, 43077. [CrossRef]

41. Dai, Z.; Noble, R.D.; Gin, D.L.; Zhang, X.; Deng, L. Combination of ionic liquids with membrane technology: A new approach for $\mathrm{CO}_{2}$ separation. J. Membr. Sci. 2016, 497, 1-20. [CrossRef]

42. Kamath, M.G.; Fu, S.; Itta, A.K.; Qiu, W.; Liu, G.; Swaidan, R.; Koros, W.J. 6FDA-DETDA: DABE polyimide-derived carbon molecular sieve hollow fiber membranes: Circumventing unusual aging phenomena. J. Membr. Sci. 2018, 546, 197-205. [CrossRef]

43. Smith, S.J.D.; Hou, R.; Lau, C.H.; Konstas, K.; Kitchin, M.; Dong, G.; Lee, J.; Lee, W.H.; Seong, J.G.; Lee, Y.M.; et al. Highly permeable Thermally Rearranged Mixed Matrix Membranes (TR-MMM). J. Membr. Sci. 2019, 585, 260-270. [CrossRef]

44. Halasa, A.F.; Wathen, G.D.; Hsu, W.L.; Matrana, B.A.; Massie, J.M. Relationship between interchain spacing of amorphous polymers and blend miscibility as determined by wide-angle X-ray scattering. J. Appl. Polym. Sci. 1991, 43, 183-190. [CrossRef]

45. Robeson, L.M. The upper bound revisited. J. Membr. Sci. 2008, 320, 390-400. [CrossRef]

(C) 2019 by the authors. Licensee MDPI, Basel, Switzerland. This article is an open access article distributed under the terms and conditions of the Creative Commons Attribution (CC BY) license (http://creativecommons.org/licenses/by/4.0/). 